Prepared for the U.S. Department of Energy

Under Contract DE-AC05-76RL01830

\title{
Software Verification and Validation Procedure
}

March 2008

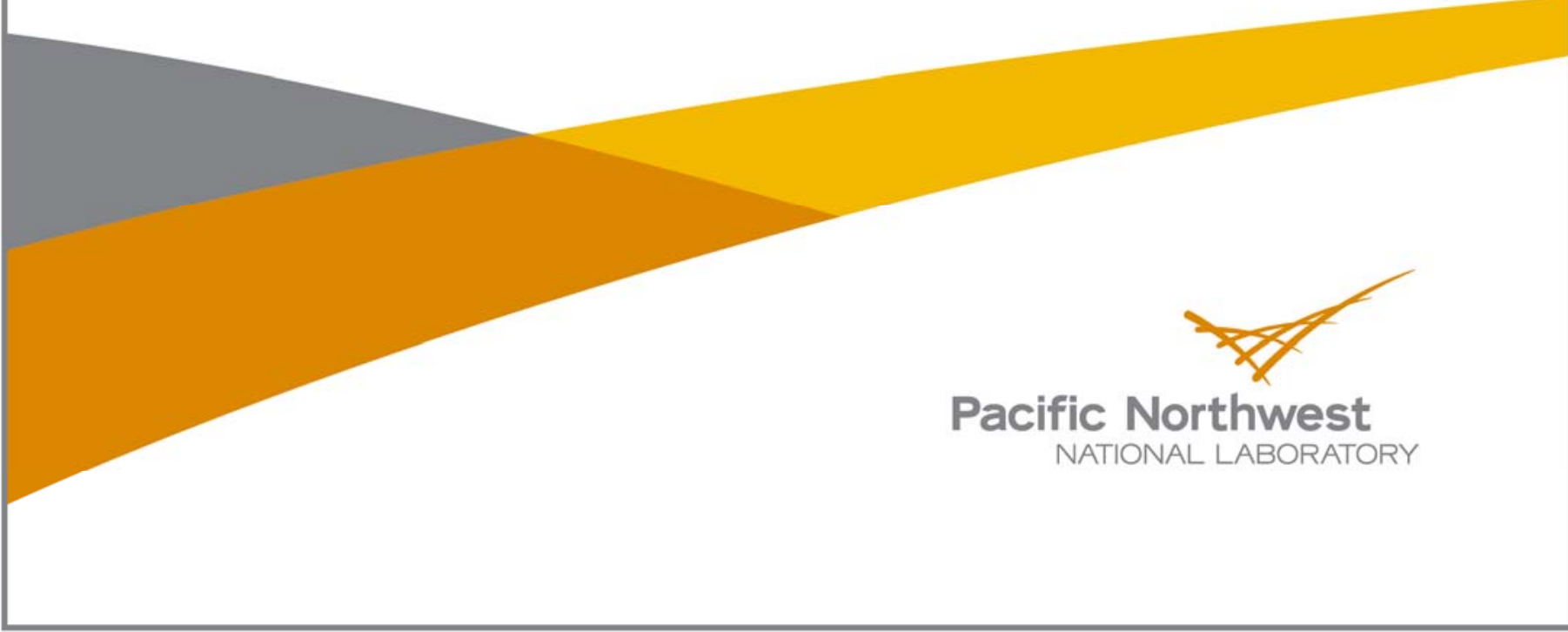




\section{DISCLAIMER}

This report was prepared as an account of work sponsored by an agency of the United States Government. Neither the United States Government nor any agency thereof, nor Battelle Memorial Institute, nor any of their employees, makes any warranty, express or implied, or assumes any legal liability or responsibility for the accuracy, completeness, or usefulness of any information, apparatus, product, or process disclosed, or represents that its use would not infringe privately owned rights. Reference herein to any specific commercial product, process, or service by trade name, trademark, manufacturer, or otherwise does not necessarily constitute or imply its endorsement, recommendation, or favoring by the United States Government or any agency thereof, or Battelle Memorial Institute. The views and opinions of authors expressed herein do not necessarily state or reflect those of the United States Government or any agency thereof.

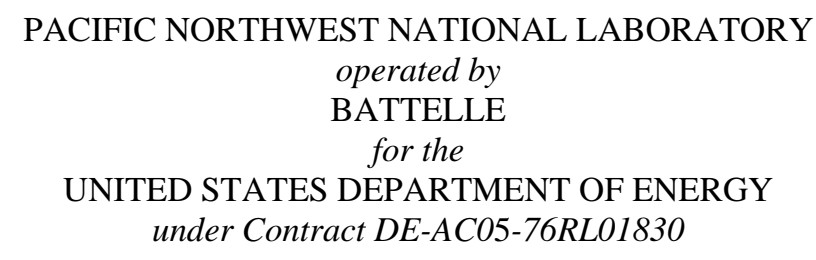

Printed in the United States of America

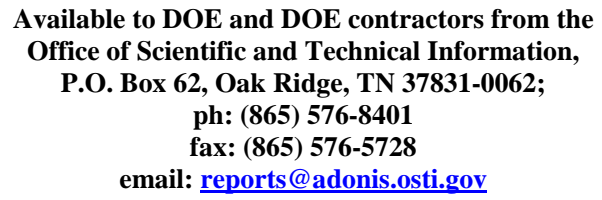

Available to the public from the National Technical Information Service, U.S. Department of Commerce, 5285 Port Royal Rd., Springfield, VA 22161 ph: (800) 553-6847 fax: (703) 605-6900

email: orders@ntis.fedworld.gov

online ordering: http://www.ntis.gov/ordering.htm 


\section{Software Verification and Validation Procedure}

March 2008

Prepared for

CH2M HILL Hanford Group, Inc.

under Contract DE-AC06-76RLO 1830

Information Sciences \& Engineering

Pacific Northwest National Laboratory

Richland, Washington 99352 



\section{Acronyms and Abbreviations}

ATPR

CRTT

DOE

IEEE

PNNL

SSEP

TWINS
Acceptance Test Plan and Results

Change Request Tracking Tool

U.S. Department of Energy

Institute of Electrical and Electronics Engineers

Pacific Northwest National Laboratory

Software Systems Engineering Process

Tank Waste Information Network System 



\section{Contents}

Acronyms and Abbreviations .................................................................................................

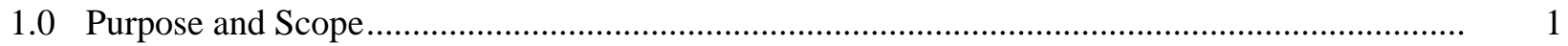

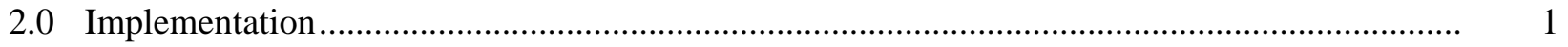

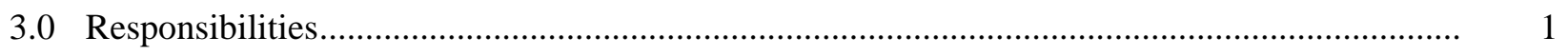

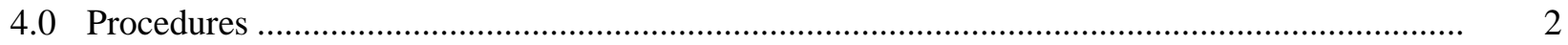

4.1 Procedure Description ............................................................................................ 2

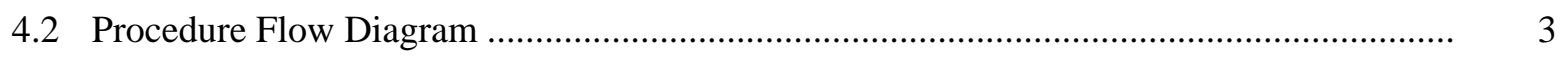

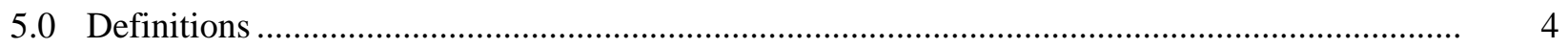

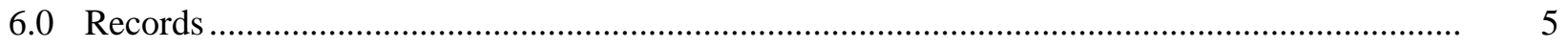

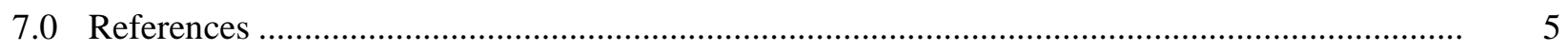

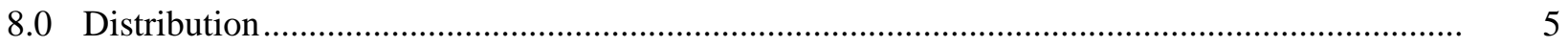

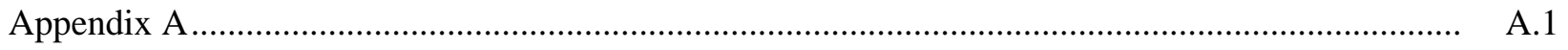

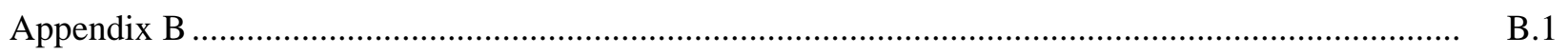

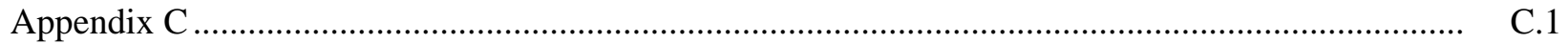





\subsection{Purpose and Scope}

This Software Verification and Validation procedure provides the action steps for the Tank Waste Information Network System (TWINS) testing process. The primary objective of the testing process is to provide assurance that the software functions as intended, and meets the requirements specified by the client. Verification and validation establish the primary basis for TWINS software product acceptance.

The TWINS project conforms to the requirements of the Pacific Northwest National Laboratory (PNNL) Information Sciences and Engineering Software Systems Engineering Process (SSEP). The SSEP has the testing process (verification and validation) integrated into its defined software lifecycle. The SSEP review and test process is defined at http://ssep.pnl.gov/VVT. The methods defined in this procedure are derived by applying a graded approach, adapting the SSEP Reviews and testing processes to the specific risks associated with the TWINS project.

This Software Verification and Validation procedure covers all software changes relating to the TWINS system. This includes web pages, scripts (server-side and client-side), code, and MS Access files (tables, reports, queries, modules).

\subsection{Implementation}

This procedure is effective on the Effective Date shown in the header above.

\subsection{Responsibilities}

Project Manager: The project manager of the TWINS project is responsible for ensuring that all aspects of this Plan are implemented. Other responsibilities are contained within Section 4.0. 


\subsection{Procedures}

\subsection{Procedure Description}

Project Manager 1 Enter the statement of work, change order, or glitch information into the Change Request Tracking Tool (CRTT).

Project Manager 2 Determine if the software change (prompted by a statement of work, change order or problem report) requires a formal Acceptance Test Plan and Results (ATPR) and enter the determination in the CRTT. If a formal test plan is required, skip to Step 8 . If a formal test plan is not required, complete steps 3 through 7 inclusive.

Note: Criteria for making a formal test plan determination are found in Attachment A.

Project Manager 3 Assign programming of the software changes to a programmer.

Programmer 4 Complete programming and perform unit testing.

Programmer 5 Notify the Independent Reviewer that programming and unit testing are complete.

Independent

6 Review each task performed by the Programmer, updating the CRTT as

Reviewer appropriate. Complete acceptance testing, documenting the results as indicated in Attachment B.

Independent

7 Enter the date of verification, verifier and the verification information of

Reviewer

Project Manager

8 Assign programmer and Independent Reviewer to complete and unit test the changes.

Independent

9 Complete ATPR per template Attachment $\mathrm{C}$ and submit to Project

Reviewer Manager for approval. In the case where CH2MHill subject matter expert(s) will perform independent testing to verify results, the programmer will act as the Independent Reviewer in that he/she will document the test results in the ATPR.

Project Manager 10 Resolve comments and concerns with Independent Reviewer and Programmer as needed and Approve ATPR.

Programmer

11 Complete programming and unit testing of changes.

Independent

12 Submit ATPR and code to Tester per protocols in the Software

Reviewer Configuration Management Plan for acceptance testing.

Tester

13 Complete acceptance testing and document on the ATPR form prepared in Step 9. If any tests fail, have the programmer make appropriate programming corrections, or correct test procedures, and rerun the tests. Indicate on the test forms or tables in ink the initials of the tester, the date of successful retest, and the notation that the test passed. 
Tester

Quality Engineer

Project Manager
14 Sign the ATPR and forward to Project Manager.

15 Review and approve the ATPR, resolving comments with the Tester as needed.

16 Maintain a file copy of the completed and approved ATPR.

\subsection{Procedure Flow Diagram}

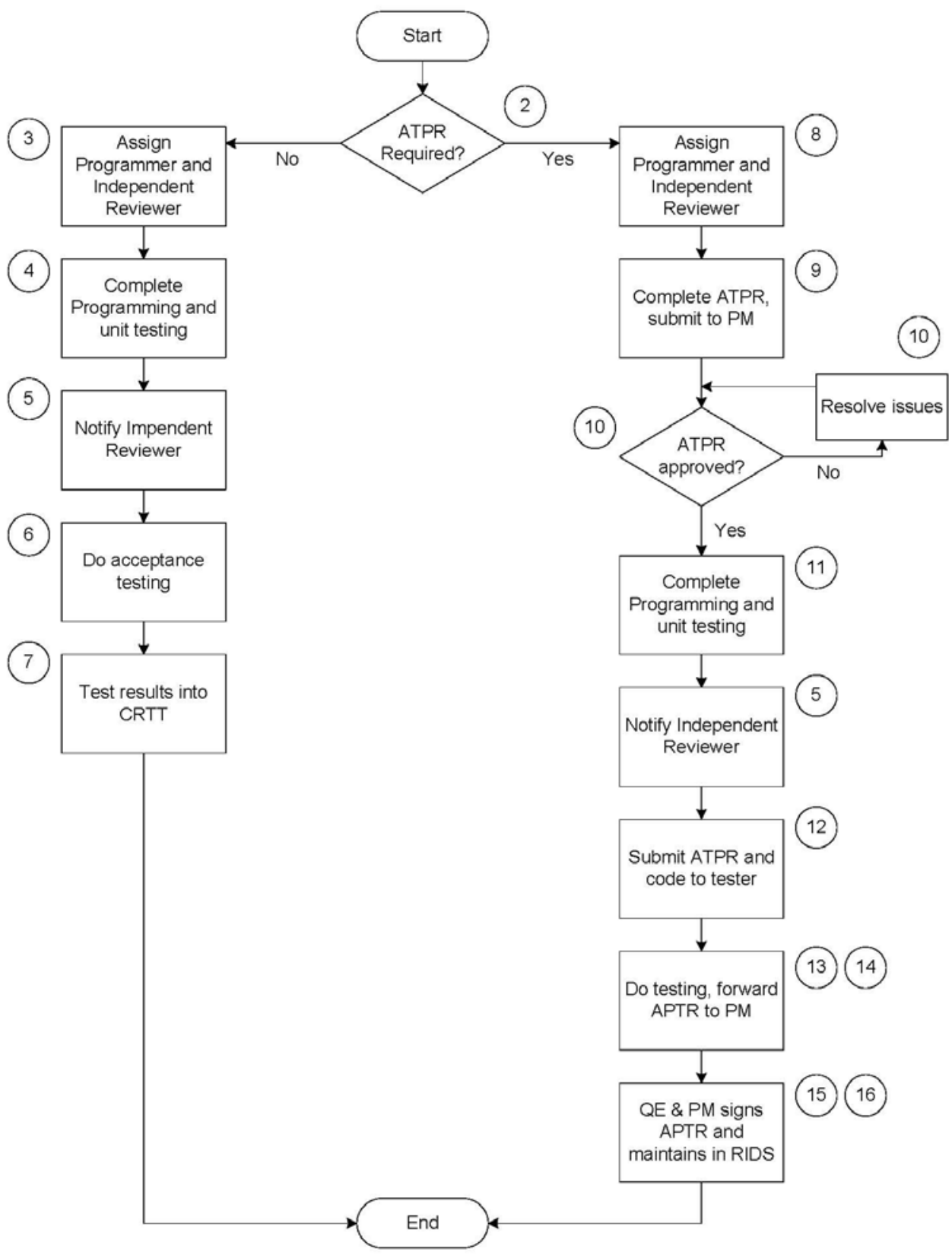




\subsection{Definitions}

Acceptance Testing

Software Verification and Validation

(from IEEE Std 610.121990, IEEE Standard

Glossary of Software Engineering

Terminology)

Unit Testing
Testing to ensure that the given requirements for a software change are met and that the overall system is not adversely affected by the change. Acceptance testing is performed by a person other than the developer. This type of testing is conducted at a higher conceptual level than Unit Testing and is focused on inputs and generated results at the user level. The scope of this type of testing includes:

1. Test cases to cover the range of possible input data, including valid and invalid values.

2. Ensuring that the system handles invalid input data appropriately to minimize the risk of generating inaccurate results.

3. Verifying the accuracy of results generated from valid input data against another trusted/verified source.

It is the judgment of the Independent Reviewer and ultimately the Project Manager that determine the scope and depth of coverage for Acceptance Testing.

If the independent testing is performed by CH2MHill subject matter expert(s), then the developer assigned to the change request or bug is responsible for documenting the test cases and results. This data will most likely be in the form of email correspondence and data dumps collected in Excel.

The process of determining whether the requirements for a system or component are complete and correct, the products of each development phase fulfill the requirements or conditions imposed by the previous phase, and the final system or component complies with specified requirements.

Testing of individual software components (stored procedures, triggers, batch executables, queries/reports, functions, subroutines, modules, and other individual classes). This testing is carried out by the developer using their knowledge of the code details. This type of testing focuses on verifying the operation of each component separately. The items generally included in this type of testing include:

1. For each variable in the component:

a. A condition inside the variable's acceptable boundaries. 
b. A condition outside the variable's acceptable boundaries.

2. Each significant logic branch or decision in the component.

3. Each significant operation or calculation that affects the output of the component.

It is ultimately the judgment of the developer that determines the degree of coverage for Unit Testing.

\subsection{Records}

Records generated by this procedure include entries into the CRTT log and the ATPR forms. Records kept prior to January 2, 2008 have been recorded in RIDS. Records after this date shall be kept in TRIM which is maintained by the Project Administrator.

\subsection{References}

1. TWINS, Software Configuration Management Plan, Revision 6, March 2008.

2. TRIM and Electronic Records Management http://cer.pnl.gov/records/trim/index.stm

\subsection{Distribution}

1. TWINS Project Manager

2. TWINS Software Developers

3. TWINS Project Quality Engineer 

Appendix A 

PNNL-17772

\section{Appendix A \\ Criteria for Determination of Need for a \\ Formal Acceptance Test Plan}

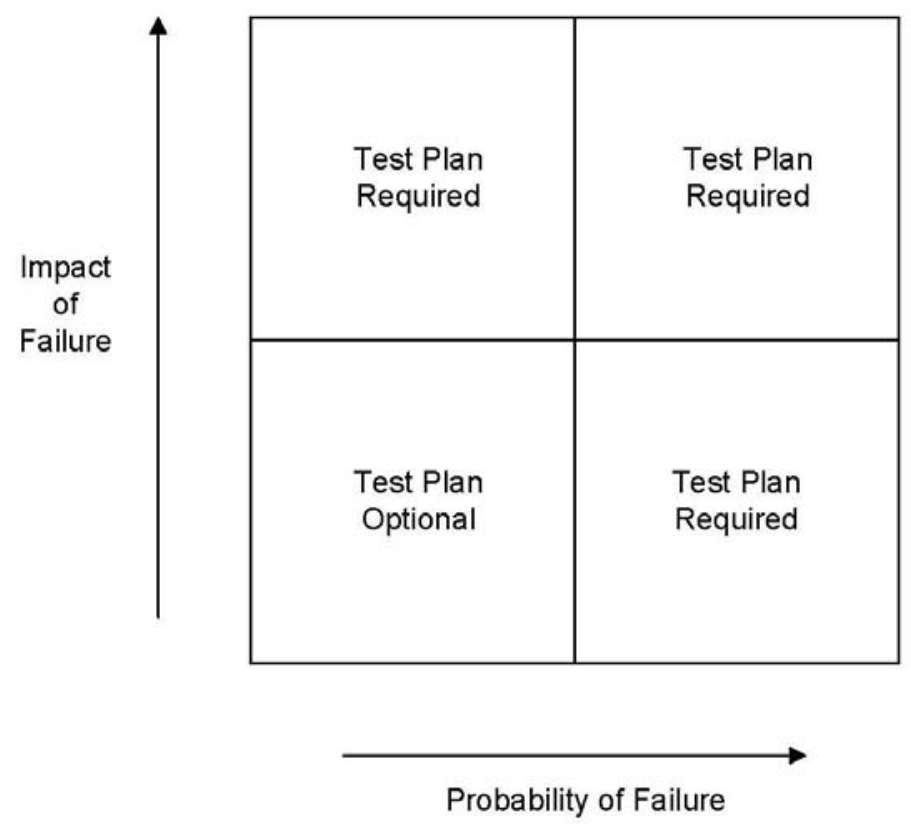

The above decision matrix defines the general criteria and process for determining whether or not a formal test plan is required for a given change. This matrix is utilized by the Project Manager as an aid in making that determination.

The "Probability of Failure" axis addresses how likely it is that the given change will be problematic. Issues typically considered in this area are listed below:

- Difficulty or complexity of change

- Size/scope of change

- Experience level of developers doing the change

The "Impact of Failure" axis addresses the implications if the given change does have problems. Issues typically considered in this area are listed below:

- Safety of workers or public compromised

- Regulatory compliance jeopardized

- Financial loss for PNNL and/or customer

- Lowered public image for PNNL, DOE, and customer

- Reduction of operational capability for PNNL and/or customer

- Compromised security of PNNL, DOE, or customer assets 

Appendix B 



\section{Appendix B Essential Information for Acceptance Test Plans and Results}

The following information is essential for documenting acceptance testing when a formal ATPR are not required:

- CRTT identification number of the change being tested

- Name of the software and revision being tested

- Tester's name, date of test

- Any special tools, conditions, or configurations needed to perform the test

- Test case descriptions, including expected outputs

- Actual results for each test case, including a "pass/fail” notation

This information is a subset of the information contained in the ATPR template provided in Attachment C. 

Appendix C 



\section{Appendix C \\ Template for Acceptance Test Plans and Results}

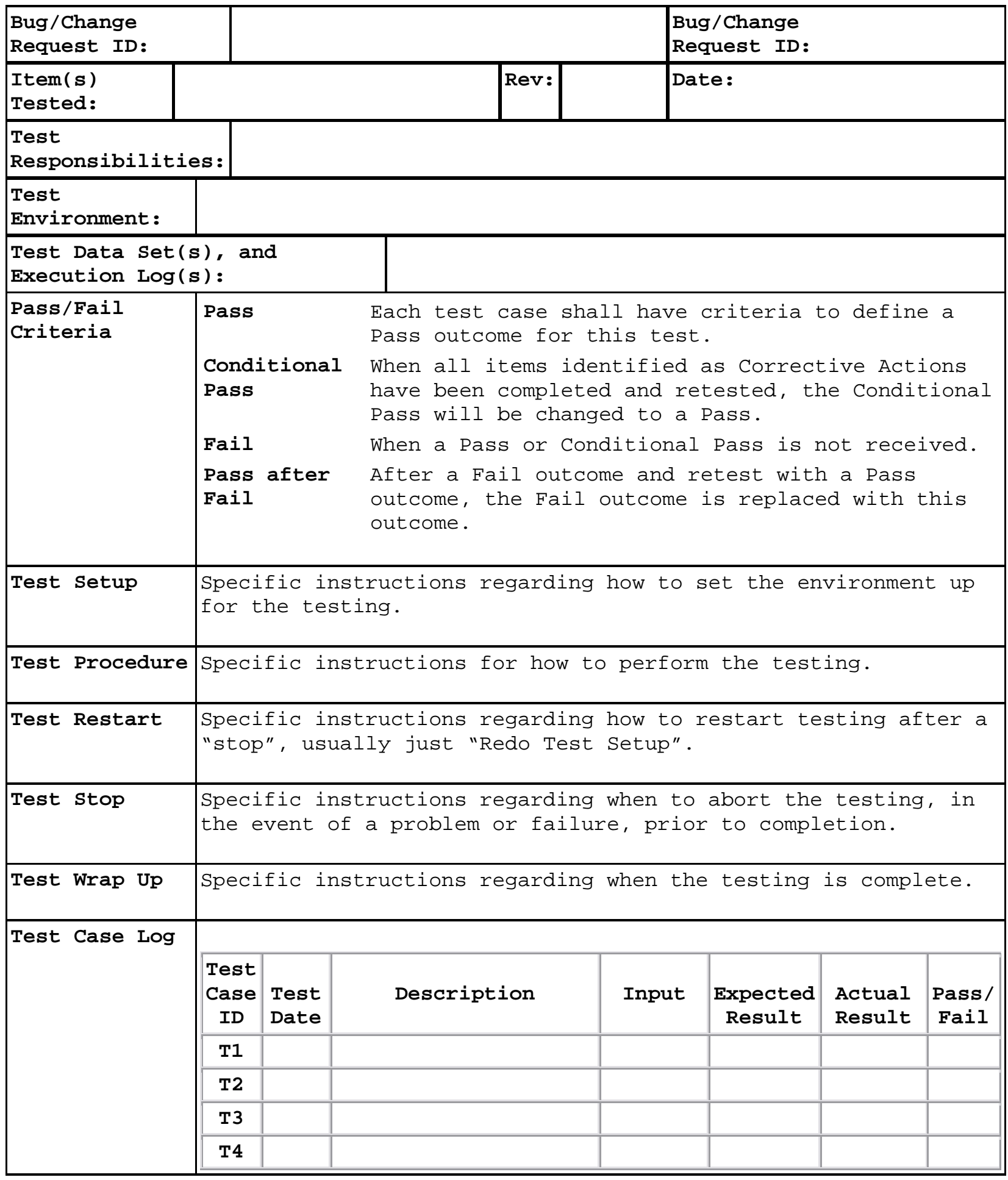


PNNL-17772

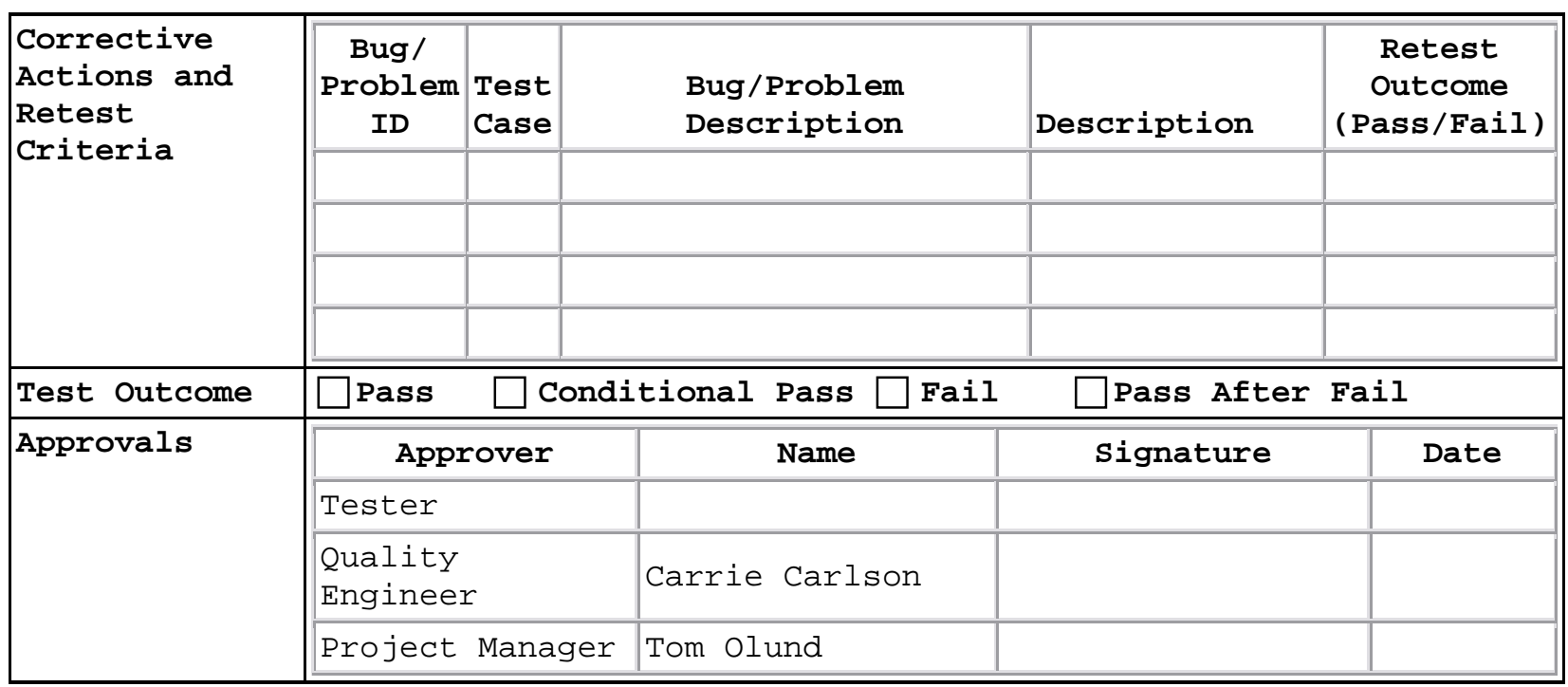





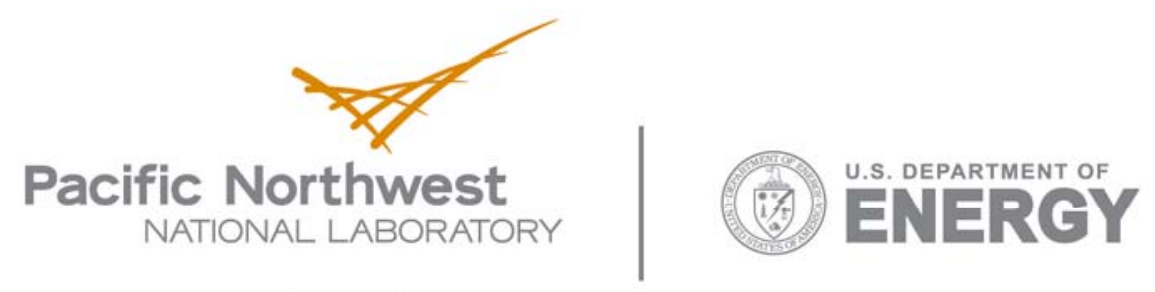

902 Battelle Boulevard

P.O. Box 999

Richland, WA 99352

1-888-375-PNNL (7665)

www.pnl.gov 